\title{
Exercise following spinal cord injury: physiology to therapy
}

\author{
This article was published in the following Dove Press journal: \\ Journal of Neurorestoratology \\ 9 December 2015 \\ Number of times this article has been viewed
}

\section{David R Dolbow}

School of Kinesiology, University of Southern Mississippi, Hattiesburg, MS, USA

Correspondence: David R Dolbow School of Kinesiology, University of Southern Mississippi, I 8 College Drive, \#5 I42, Hattiesburg, MS 39406, USA

Tel +l 60I 2666249

Email david.dolbow@usm.edu
Abstract: Spinal cord injuries (SCIs) can have catastrophic effects on individuals resulting in loss of physical abilities and independence. Loss of the ability to perform activities of daily living reduces the quality of life. Furthermore, decreased ability to perform physical activities decreases overall fitness and increases the risk of diseases related to sedentary lifestyle. Activitybased restorative therapies (ABRTs) provide an option to help optimize rehabilitation through the restoration of function and the introduction to physical activities via adapted equipment. ABRT programs are typically located in SCI centers, which limit long-term access to those not living near the facilities. Typical rehabilitation clinics not specializing in SCI care are able to provide modified ABRT programs, but lack the staffing and adaptive equipment provided in the larger SCI rehabilitation centers. For long-term rehabilitation and wellness needs, the placement of adaptive equipment in the homes of those with SCI has proven to be beneficial, although costly as highly technical equipment such as functional electrical stimulation cycles usually cost over US\$20,000. Community fitness centers offer some possible options for long-term exercise through inclusive fitness programs but many still lack full accessibility for those who are wheelchair reliant and most do not provide specialized adaptive equipment or trained staff to meet the special needs of individuals with SCI and other paralytic conditions. It is important for health care providers to continue to advocate for useful and less expensive adaptive equipment that may provide exercise to paralyzed muscles and greater access and accommodation of wheelchair-reliant individuals by community fitness centers.

Keywords: activity-based restorative therapies, functional electrical stimulation, body-weightsupported treadmill training

\section{Introduction}

Spinal cord injury (SCI) can result in full or partial paralysis, which limits mobilityproducing muscular activation. Reduced mobility decreases the body's ability to complete functional activities resulting in decreased capacity to complete typical activities of daily living. Dysfunction related to activities of daily living often negatively impacts quality of life (QOL) through decreased independence. Compounding the problem of decreased function, decreased mobility can be an impediment toward maintaining the requisite amount of physical activity for maintaining health. Individuals with disabilities have been reported to have physical activity levels that are approximately $60 \%$ below that of the able-bodied population. ${ }^{1}$ Considering these factors, it is not surprising that individuals with SCI have been found to have an increased incidence of conditions associated with physical inactivity. These conditions include heart disease, atherosclerosis, metabolic syndrome, diabetes mellitus, obesity, and osteoporosis. ${ }^{2-4}$ 


\section{Functional limitations after $\mathrm{SCl}$}

An SCI results in a complex series of events that include a lesion within the spinal cord, glial scarring around the lesion, release of chemicals that inhibit axonal growth in the damaged area, and axonal demyelination of nearby but initially unaffected neurons. ${ }^{5}$ Disability related to SCI depends on the completeness of injury and the level of injury. When there is preservation of sensation and/or motor activity below the neurological level of insult that includes the lowest sacral segments (S4-S5), the injury is termed incomplete. When the lowest sacral levels are without sensory and motor activity, the injury is termed complete. ${ }^{6}$ The more complete the injury the greater the level of impairment. Likewise, the higher the level of injury within the spinal cord the greater the impairment. Impairment increases with the involvement of each successive spinal nerve segment advancing cephalically.

The terms tetraplegia (injury to cervical segmental levels) and paraplegia (injury below cervical neural segmental levels) are commonly used but less precise than the American Spinal Injury Association Impairment Scale (AIS). ${ }^{6}$ The AIS is a more accurate and specific approach of categorizing both motor and sensory impairment. This scale identifies the sensory and motor levels as indicated by the most rostral spinal levels with unimpaired function. ${ }^{6,7}$

\section{American Spinal Injury Association Impairment Scale}

A. (Complete) - no sensory or motor function is preserved in the sacral segments S4-S5.

B. (Sensory incomplete) - sensory but not motor function is preserved below the neurological level and includes the sacral segments S4-S5 (light touch, pin prick at S4-S5, or deep anal pressure), AND no motor function is preserved more than three levels below the motor level on either side of the body.

C. (Motor incomplete) - motor function is preserved below the neurological level and more than half of key muscle functions below the single neurological level of injury have a muscle grade less than 3 .

D. (Motor incomplete) - motor function is preserved below the neurological level and at least half of key muscle functions below the neurological level of injury have a muscle grade of 3 or greater.

E. (Normal) - if sensation and motor function as tested with the International Standards for Neurological Classification of Spinal Cord Injury are graded as normal in all segments, and the patient had prior deficits, then the AIS grade is $\mathrm{E}$.
Particular segmental areas of interest regarding functional loss includes injury to the sacral segments S4-S5 leading to complications involving the loss of control of bowel and bladder causing urinary tract dysfunction, which increases the risk of infections. ${ }^{8,9}$ Urinary tract infections are the most frequent secondary medical complication among those with SCI. ${ }^{10}$

Injury to the thoracic region of the spine results in impairment of the trunk in addition to the legs and pelvis. The higher the injury in the thoracic region, the greater the impairment to trunk musculature resulting in increasingly less ability to maintain trunk posture and sitting balance. When the injury level is at or above the T6 segmental level, autonomic control may be involved resulting in the possibility of uncontrolled outflow of the sympathetic nervous system in response to a stimuli that would ordinarily not cause an adverse reaction, that is, autonomic dysreflexia. The perceived noxious stimulus can be as simple as a kinked catheter, tight shoe lace, or sitting on a wrinkled seat cushion and can result in life-threatening reflex bradycardia, bradyarrhythmia, and hypertension. ${ }^{9}$ While injuries to the lumbosacral and thoracic regions involve the trunk and legs, they do not involve the arms; whereas, injuries to the cervical spine involve the arms, shoulders, and neck as well as everything innervated by spinal segments below. Over $56 \%$ of the $\sim 11,000$ new SCI cases each year in the USA are categorized as tetraplegia. ${ }^{11}$ Complete tetraplegia and resultant impairments in the arms, trunk, and legs produce catastrophic disabilities. The ability to perform activities of daily living such as eating, brushing teeth, dressing, and the like are limited or absent. Serious respiratory conditions can arise from a cervical spine injury that may have major implications on the quality and length of life. In fact, a primary cause of death among those with SCI is due to respiratory complications. ${ }^{11,12}$ Any injury to the cervical region may affect transmission to thoracic and abdominal musculature decreasing respiratory efficiency; however, phrenic nerve innervation of the diaphragm is through the C3-C5 spinal segments, thus damage at these levels results in various levels of paralysis of the diaphragm, which can greatly impair respiration possibly requiring mechanical respiratory assistance. Injury above this level will eliminate voluntary ventilation. ${ }^{9,11}$

Paralysis results in dramatic reductions in functional abilities and can have a devastating effect on an individual's health and QOL. However, the chronic effects of paralysis can further produce physiological secondary medical conditions for individuals with SCI. 


\section{Physiological effects after $\mathrm{SCl}$}

While SCI produces a number of effects on the various bodily systems, this paper will focus on the musculoskeletal system. Many changes due to paralysis are easily recognized and measured in the muscular system due to rapid atrophy over the first year postinjury. The degenerative effects on muscle below the level of injury stems from partial or total disruption of neural transmission across and below the level of injury. The elimination of nervous stimulation to skeletal muscle results in major disorganization and breakdown of the structure of contractile fibers. ${ }^{13}$ The ratio of slow-twitch oxidative to fast-twitch glycolytic muscle fibers shifts toward the less fatigue resistant fast-twitch fibers. ${ }^{14-18}$ Decreased muscle mass is typically a visible and measureable result. Using magnetic resonance imaging, loss of muscle cross-sectional area below the level of injury has been reported to be $18 \%-46 \%$ in just 6 weeks. ${ }^{19}$ Decreases in muscle cross-sectional area have been reported to be between $45 \%$ and $80 \%$ after 6 months postinjury. ${ }^{19-21}$ Gorgey and Dudley ${ }^{20}$ also reported an increase in intramuscular fat by $126 \%$ just 6 weeks postinjury and a threefold buildup of intramuscular fat 6 months after SCI. This indicates that muscle not only decreases in mass, but also deteriorates with respect to muscle quality.

Skeletal muscle atrophy has been linked to a number of unhealthy conditions, which may stem from the resulting changes in the proportion of muscle to fat ratio of the body. Decreased muscle mass is associated with a lowering of basal metabolic rate, which disrupts the energy balance equation (energy consumed - energy burned $=$ stored energy). Thus, decreased energy use due to decreased available metabolic muscle disrupts the equation causing increased energy storage giving rise to obesity. Prevalence of obesity within the SCI population is estimated to be as high as $66 \% .^{22-25}$ Obesity is a well-known risk factor for cardiovascular disease, metabolic syndrome, diabetes mellitus, and all-cause mortality. ${ }^{3,22}$ Duckworth et al ${ }^{26}$ reported that nearly $50 \%$ of the 45 participants in a study of individuals with chronic SCI had problems related to type 2 diabetes, while Bauman and Spungen ${ }^{27}$ reported that individuals with SCI had a greater than threefold risk of type 2 diabetes compared with controls.

Likewise, chronic SCI can have a dramatic deleterious effect on bone. Bone mineral density (BMD) varies throughout life and is largely impacted by the ratio of bone productive osteoblast activity and bone destructive osteoclast activity. The dynamic process of bone synthesis typically begins with continued positive net bone formation through childhood and early adulthood until BMD peaks before giving way to a gradual negative net BMD in the late 20s or early $30 \mathrm{~s}$, which is generally associated with aging. ${ }^{28}$ While factors such as sex, race, diet, and physical activity impact $\mathrm{BMD}$, muscle paralysis has been shown to have a major impact, which frequently leads to pathologic levels of BMD. Individuals may experience a rapid bone loss of between $20 \%$ and $50 \%$ in the lower extremities within the first few years post-SCI. ${ }^{29-32}$ Garland et al ${ }^{33}$ reported a 33\% loss of BMD in the legs within 3-4 months post-SCI, while as much as $50 \%$ loss in BMD was reported in 3 years post-SCI. Thereafter, bone loss plateaus and reaches steady state approximately 4 years post-SCI. ${ }^{34}$ Bone loss after SCI is regional with the greatest areas of loss being below the level of injury and in the trabecular bone-rich areas of the proximal epiphysis and metaphysis of the femur and proximal and distal tibia. ${ }^{30,34-36}$ Individuals with SCI are at greater risk of osteoporosis and osteopenia. Otom and Al-Ahmar ${ }^{37}$ reported that $83.6 \%$ of 55 SCI study participants had demonstrated abnormal BMD with $40 \%$ being osteoporotic and $43.6 \%$ being osteopenic. ${ }^{29}$ Osteoporosis has been shown to increase the risk of bone fracture including a greater risk of low trauma or fragility fractures. ${ }^{30}$ Fragility fractures can be defined as a bone fracture from a trauma that would ordinarily not cause a fracture such as a fall from standing height or less. In fact, most fractures after SCI occur during normal activities of daily living such as transferring, bathing, and dressing. Risk of fracture has been shown to increase with the length of time after injury with some fracture rates reported to be as high as $14 \%$ within 5 years of injury, $28 \%$ within 10 years, and $39 \%$ within 15 years of injury. ${ }^{38}$ The method for determining osteoporosis and increased bone fracture risk was established from data using able-bodied individuals and is less accurate for those with SCI. For the general population, BMD is measured at the lumbar spine, hip, and nondominant wrist via dual energy X-ray absorptiometry. However, because the region of bone most commonly fractured differs between the able-bodied population and those with SCI, Shields et al ${ }^{39}$ devised a method to reliably measure the distal femur and proximal tibia using dual energy X-ray absorptiometry. This procedure may assist in more accurately assessing fracture risk for those with SCI.

Because of the complexity of functional and physiological effects after SCI, the rehabilitation of individuals with $\mathrm{SCI}$ is also complex.

\section{Physical rehabilitation after $\mathrm{SCl}$}

Over the past couple decades, there has been a gradual paradigm shift of the philosophy guiding SCI rehabilitation. There was once a belief that the central nervous system was 
hardwired with no hope of restoration of function. This produced the notion that once injured, individuals should concentrate on compensation for lost function with braces, wheelchairs, and other assistive devices as restoration of lost function was not viable. While compensation for lost motor activities is a necessary part of physical rehabilitation training, today it is typically coupled with attempts to restore as much function as possible through neuroplasticity. Neuroplasticity can be defined as the ability of the nervous system to reorganize itself by forming new neural connections in the brain and spinal cord. Neuroplasticity allows the neurons to compensate for injury and disease and appears to be driven at least in part by physical activity.

A therapy format that attempts to optimize neuroplasticity for restoration of function using skilled rehabilitation techniques through improved movement skills with or without assistive devices and promotes overall wellness reducing the risk of secondary medical conditions is referred to as activity-based restorative therapies (ABRTs). This high-intensity and high-volume approach has developed over the past decade and depends on five key components: 1) weight-bearing activities, 2) functional electrical stimulation (FES), 3) task-specific practice, 4) massed practice, and 5) locomotor training (body weight supported via overhead harness or via buoyancy of water in a therapeutic pool) to optimize results. ${ }^{5,40,41}$

Weight-bearing activities include a wide variety of activities such as assisted or braced standing, sitting with or without arm support, quadruped (arms and legs engaged), and kneeling. Weight-bearing activities are preferred in order to maximize neurostimulation above and below the level of injury. ${ }^{5}$ Weight-bearing activities such as standing not only enhances the actual standing ability, but also has been shown to positively impact QOL, decrease risk of pressure ulcers, and improve bowel and bladder health. ${ }^{42}$ FES activities are physical training activities that use external electrical stimulation to assist weak muscles or induce activity in paralyzed muscles. These FES activities may include cycling, ambulation, standing, transferring, rowing, or other specific movements. ${ }^{5} \mathrm{FES}$ activities in rodent studies have produced the birth of tripotential endogenous neural progenitor cells in the spinal cord as well as axonal regeneration of damaged neurons. ${ }^{5,43,44}$ Regarding body composition, FES exercise has been shown to increase muscle mass, decrease fat mass, and improve BMD below the level of injury. ${ }^{45-47}$ Dermchak et al ${ }^{47}$ found a $63 \%$ increase in the cross-sectional area of the vastus lateralis muscle in individuals with SCI after FES cycling for 30 minutes three times per week for 13 weeks. Along with increased muscle mass, Petrie et $\mathrm{l}^{48}$ found that a minimal dose ( $\sim 10$ minutes per day) of electrically induced exercise to the soleus muscle continued for over a year prompted the restoration of oxidative slow-twitch phenotypes, which may assist in decreasing the risk of diabetes and other metabolic diseases. Adams et $\mathrm{al}^{49}$ found similar results in regulating muscle fiber type by inducing a reduction of ten mRNAs that mediate fast-twitch muscle contractions and increasing 69 mRNAs that mediate slow-twitch oxidative contractions with electrical stimulation training to the soleus muscle over 6 years. Likewise, Shields and Dudley-Javoroski ${ }^{50}$ found positive body composition restoration with a $31 \%$ increase in BMD of the distal tibia after using electrical stimulation to the soleus muscle at 1.5 times body weight five times weekly for 2-3 years. Additional benefits found in humans via externally stimulated muscle contractions include increased cardiovascular fitness and decreased risk of gluteal pressure ulcers after FES cycling three times per week for at least 2 months. ${ }^{51-55}$

Task-specific practice is a critical element as it targets activities that are specific to the rehabilitation goals of the patient such as walking, moving from a lying position to sitting, sitting to standing, and the like. It allows the patient to work on specific tasks that they feel are important to their recovery. ${ }^{5}$ Massed practice refers to the large number of repetitions that are performed during the 5 or more hours of therapy per day. Locomotor training is the final component and is often the most desired because restoration of ambulation is typically a goal for those that have lost the ability to walk. Locomotor training can take many forms depending on the specific abilities of the patient. Body-weight-supported treadmill training is an activity in which the patient is partially supported by an overhead cable as specially trained technicians use hand placement for tapping and applying pressure to specific muscle tendons or bellies to illicit muscle contractions needed for walking. One key factor is that as many as four technicians or therapists must coordinate their activities with each other and the patient's efforts to produce a correct walking gait. This is a labor-intensive activity for the patient and the staff members. Body-weight-supported treadmill training can also be performed in a therapeutic pool using the buoyancy of the water to decrease weight bearing and by having the technicians use their feet to assist with muscle activity facilitation. Patients are advanced to overground walking with various assistive devices and assistance from staff members as the patient progresses. ${ }^{5}$ Body-weight-supported treadmill training and water treadmill training have both been reported as promoting enhancement of walking ability in individuals 
after SCI ${ }^{56-58}$ ABRT is labor intensive and requires greater staffing than many rehabilitation facilities can provide, thus ABRT programs are usually modified to match the available staffing and equipment resources of the facility.

ABRT is a way to optimize recovery and initiate physical activity needed to promote wellness and reduce the risk of secondary conditions associated with chronic SCI and chronically low physical activity levels. However, clinically based treatments such as ABRT cannot last forever and once the program has ended individuals with SCI frequently encounter external barriers to community-based physical activities.

\section{Inclusive fitness}

After clinical rehabilitation services have ended, patients are typically provided a home exercise program to continue training for rehabilitation and wellness purposes. This works well for the rehabilitation of many conditions, however for those with SCI, paralysis can present limitations in the performance of self-exercise. Individuals with SCI and other paralytic conditions require specialized adaptive equipment to meet their needs. One option is to have the patient purchase this equipment, however, adapted equipment can be quite costly as mentioned earlier and individuals with SCI are typically more sedentary than their able-bodied peers. However, in a study designed to measure the exercise adherence rate of 17 individuals with chronic SCI when FES cycles were placed in the home, exercise adherence rates were much higher than the reported $35 \%$ of able-bodied individuals who adhere to daily recommended physical activity levels for maintaining health. ${ }^{4}$ Participants were asked to cycle for 40-60 minutes three times per week over 16 weeks. Exercise adherence rates were $71.7 \%$ for the first 8 weeks and $62.9 \%$ for the second 8 -week period. ${ }^{4}$ Nevertheless, with the cost of FES cycles exceeding US\$20,000, the feasibility of placing this type of specialized equipment in the homes of those who would benefit is low. As technology concerning adapted equipment for those with paralysis advances, it is hoped that the development of adequate lower cost functional FES equipment will emerge.

Another option is to utilize community fitness centers, however, even with the Americans with Disabilities Act (ADA) of 1990, which mandates equal access to public facilities for all, there appears to be a lack of accessibility and accommodation for wheelchair-reliant individuals. Figoni et $\mathrm{al}^{59}$ examined the ADA compliance rates of community fitness centers in the Kansas City, MO area and found that no facilities were $100 \%$ compliant, with a major problem being the lack of free passage to and around exercise equipment and the absence of full accessibility to restrooms and locker rooms. In a more recent similar study in the southeastern USA, community fitness facilities were found to be lacking in access to exercise equipment and beyond ADA requirements, few provided specialized adaptive equipment or staff members who were knowledgeable in the special needs of individuals with paralytic conditions. ${ }^{60}$ Thus, a key for the advancement of inclusive fitness for those with SCI and other paralytic conditions is to encourage and assist community fitness centers to move from partially accessible and accommodating to fully accessible and accommodating for those who are wheelchair reliant.

\section{Conclusion}

The catastrophic effects of SCI can be far reaching, resulting in loss of independence and increased risk of inactivity-based medical conditions. ABRT provides one option to help optimize rehabilitation through the restoration of function and the introduction to physical activities via adapted equipment. Rehabilitation centers that specialize in SCI treatment are at best regionally based, thus can be difficult for all individuals with SCI to access. Typical rehabilitation clinics not specializing in SCI care are able to provide modified ABRT programs but lack the staffing and adaptive equipment provided in the larger SCI rehabilitation centers. Community fitness centers offer some possible options but many still lack full accessibility for those who are wheelchair reliant and most do not provide specialized adaptive equipment or trained staff to meet the special needs of individuals with SCI and other paralytic conditions. It is important for health care providers to continue to advocate for useful but less expensive adaptive equipment that may exercise paralyzed muscles and greater access and accommodation of wheelchair-reliant individuals by community fitness centers.

\section{Disclosure}

The author reports no conflict of interest in this work.

\section{References}

1. van den Berg-Emons RJ, Bussmann JB, Haisma JA, et al. A prospective study on physical activity levels after spinal cord injury during inpatient rehabilitation and the year after discharge. Arch Phys Med Rehabil. 2008;89(11):2094-2101.

2. Burr JF, Shephard RJ, Zehr EP. Physical activity after stroke and spinal cord injury. Can Fam Physician. 2012;58:1236-1239.

3. Gater DR. Obesity after spinal cord injury. Phys Med Rehabil Clin N Am. 2007;18:333-351.

4. Dolbow DR, Gorgey AS, Ketchum JM, Moore JR, Hackett LA, Gater DR. Exercise adherence during home-based functional electrical stimulation cycling by individuals with spinal cord injury. Am J Phys Med Rehabil. 2012;91(11):922-930. 
5. Dolbow DR, Gorgey AS, Recio AC, et al. Activity-based restorative therapies after spinal cord injury: inter-institutional conceptions and perceptions. Aging Dis. 2015;6(4):254-261.

6. Kirshblum SC, Burns SP, Biering-Sorensen F, et al. International standards for neurological classification of spinal cord injury. J Spinal Cord Med. 2011;34(6):535-546.

7. American Spinal Injury Association. International Standards for Neurological Classification of Spinal Cord Injury. Available from: www.asia-spinalinjury.org/elearning/ASIA_ISCOS_high.pdf. Accessed October 5, 2015.

8. Figoni SF. Spinal cord disabilities: paraplegia and tetraplegia. In: Durstine JL, Moore GE, editors. ACSM's Exercise Management of Persons with Chronic Diseases and Disabilities. Champaign, IL: Human Kinetics; 2003:247-253.

9. Gater DR. Spinal cord injury In: Ehrman JK, Gordon PM, Visich PS, Keteyian SJ, editors. Clinical Exercise Physiology. Champaign, IL: Human Kinetics; 2003:503-526.

10. Fuller KS. Traumatic spinal cord injury In: Goodman CC, Boissonnault WG, Fuller KS, editors. Pathology: Implications for the Physical Therapist. Philadelphia, PA: Saunders; 2003:1086-1097.

11. Zimmer MB, Nantwi K, Goshgarian HG. Effect of spinal cord injury on the respiratory system: basic research and current clinical treatment options. J Spinal Cord Med. 2007;30(4):319-330.

12. Winslow C, Rozovsky J. Effects of spinal cord injury on the respiratory system. Am J Phys Med Rehabil. 2003;82:803-814.

13. Boncompagni S. Severe muscle atrophy due to spinal cord injury can be reversed in complete absence of peripheral nerves. Eur J Transl Myol - Basic Appl Myol. 2012;22(4):161-200.

14. Shield RK. Fatigability, relaxation properties, and electromyographic responses of the human paralyzed soleus muscle. J Neurophysiol. 1995;73(6):2195-2206.

15. Shields RK, Law LF, Reiling B, Sass K, Wilwert J. Effects of electrically induced fatigue on the twitch and tetanus of paralyzed soleus muscle in humans. J Appl Physiol. 1997;1985(82):1499-1507.

16. Burnham R, Martin T, Stein R, Bell G, MacLean I, Steadward R. Skeletal muscle fibre type transformation after spinal cord injury. Spinal Cord. 1997;35(2):86-91.

17. Gerrits HL, De Haan A, Hopman MT, van Der Woude LH, Jones DA, Sargeant AJ. Contractile properties of the quadriceps muscle in individuals with spinal cord injury. Muscle Nerve. 1999;22(9): 1249-1256.

18. Shields RK, Dudley-Javoroski S. Musculoskeletal adaptations in chronic spinal cord injury: effects of long-term soleus electronic stimulation training. Neurorehabil Neural Repair. 2007;21(2):169-179.

19. Castro MJ, Apple DF Jr, Hillegass EA, Dudley GA. Influence of complete spinal cord injury on skeletal muscle cross-sectional area within the first 6 months of injury. Eur J Appl Physiol Occup Physiol. 1999;80(4):373-378.

20. Gorgey AS, Dudley GA. Skeletal muscle atrophy and increased intramuscular fat after incomplete spinal cord injury. Spinal Cord. 2007;45(4):304-309.

21. Biering-Sørensen B, Kristensen IB, Kjaer M, Biering-Sørensen F. Muscle after spinal cord injury. Muscle Nerve. 2009;40(4):499-519.

22. Eriks-Hoogland I, Hilfiker R, Baumberger M, Sarah B, Gerold S, Perret C. Clinical assessment of obesity in persons with spinal cord injury: validity of waist circumference, body mass index, and anthropometric index. J Spinal Cord Med. 2011;34(4):416-422.

23. Anson CA, Shepherd C. Incidence of secondary complications in spinal cord injury. Int J Rehabil Res. 1996;19(1):55-66.

24. Chen YM, Ho SC, Lam SS, Chan SS. Validity of body mass index and waist circumference in the classification of obesity as compared to percent body fat in Chinese middle-aged women. Int J Obes (Lond). 2006;30(6):918-925.

25. Liang H, Chen D, Wang Y, Rimmer JH, Braunschweig CL. Different risk factor patterns for metabolic syndrome in men with spinal cord injury compared with able-bodied men despite similar prevalence rates. Arch Phys Med Rehabil. 2007;88(9):1198-1204.
26. Duckworth WC, Jallepalli P, Solomon SS. Glucose intolerance in spinal cord injury. Arch Phys Med Rehabil. 1983;64:107-110.

27. Bauman WA, Spungen AM. Disorder of carbohydrate and lipid metabolism in veterans with paraplegia or quadriplegia: a model of premature aging. Metabolism. 1994;43(6):749-754.

28. Heaney RP, Abrams S, Dawson-Hughes B, Looker A, Marcus R, Matkovic V. Peak bone mass. Osteoporosis Int. 2000;11:985-1009.

29. Dolbow JD, Dolbow DR, Gorgey AS, Adler RR, Gater DR. The effects of aging and electrical stimulation exercise on bone after spinal cord injury. Aging Dis. 2013;4(3):141-153.

30. Dolbow DR, Gorgey AS, Daniels JA, Adler RR, Gater DR Jr. The effects of spinal cord injury and exercise on bone mass: a literature review. NeuroRehabilitation. 2011;29(3):261-269.

31. Sheilds RK. Muscular, skeletal, and neural adaptations following spinal cord injury. J Orthop Sports Phys Ther. 2002;32(2):65-74.

32. Biering-Sorensen F, Bohr H, Schaadt O. Bone mineral content of the lumbar spine and lower limbs years after spinal cord lesion. Paraplegia. 1988;26:293-301.

33. Garland DE, Stewart CA, Adkins RH, et al. Osteoporosis after spinal cord injury. J Orthop Res. 1992;10(3):3871-3878.

34. Dudley-Javoroski S, Shields RK. Regional cortical and trabecular bone loss after spinal cord injury. J Rehabil Res Dev. 2012;49(9): 1365-1376.

35. Eser P, Frotzler A, Zehnder Y, et al. Relationship between the duration of paralysis and bone structure: a pQCT study of spinal cord injured individuals. Bone. 2004;34(5):869-880.

36. Dauty M, Perrouin Verbe B, Maugars Y, Dubois C, Mathe JF. Supralesional and sublesional bone mineral density in spinal cordinjured patients. Bone. 2000;27(2):305-309.

37. Otom AH, Al-Ahmar MR. Bone loss following spinal cord injury. J Neurorestoratol. 2014;2:81-84.

38. Maynard FM, Karunas RS, Adkins RH, et al. Management of the neuromuscular system. In: Stover SL, Delisa JA, Whiteneck GG, editors. Spinal Cord Injury: Clinical Outcomes of the Model Systems. Gaithersburg, MD: Aspen Publishers; 1995:145-169.

39. Shields RK, Schlechte J, Dudley-Javoroski S, et al. Bone mineral density after spinal cord injury: a reliable method for knee measurement. Arch Phys Wed Rehabil. 2005;86(10):1969-1973.

40. Sadowsky CL, McDonald JW. Activity-based restorative therapies: concepts and applications in spinal cord injury-related neurorehabilitation. Dev Disabil Res Rev. 2009;15(2):112-116.

41. Martin R, Sadowsky C, Obst K, Brooke M, McDonald J. Functional electrical stimulation in spinal cord injury: from theory to practice. Top Spinal Cord Inj Rehabil. 2012;18(1):28-33.

42. Walter JS, Sola PG, Sacks J, Lucero Y, Langbein E, Weaver F. Indications for a home standing program for individuals with spinal cord injury. $J$ Spinal Cord Med. 1999;22(3):152-158.

43. Becker D, Gary DS, Rosenzweig ES, Grill WM, McDonald JW. Functional electrical stimulation helps replenish progenitor cells in the injured spinal cord of adult rats. Exp Neurol. 2010;222(2):211-218.

44. Li Q, Brus-Ramer M, Martin JH, McDonald JW. Electrical stimulation of the medullary pyramid promotes proliferation and differentiation of oligodendrocyte progenitor cells in the corticospinal tract of the adult rat. Neurosci Lett. 2010;479(2):128-133.

45. Gorgey AS, Mather KJ, Cupp HR, Gater DR. Effects of resistance training on adiposity and metabolism after spinal cord injury. Med Sci Sports Exerc. 2012;44(1):165-174.

46. Frotzler A, Coupaud S, Perret C, et al. High-volume FES-cycling partially reverses bone loss in people with chronic spinal cord injury. Bone. 2008;43(1):169-176.

47. Dermchak TJ, Linderman JK, Mysiw WJ, Jackson R, Suun J, Devor ST. Effects of functional electric stimulation cycle ergometry training on lower limb musculature in acute SCI individuals. J Sports Sci Med. 2005;4:263-271.

48. Petrie MA, Suneja M, Faidley E, Shields RK. A minimal dose of electrically induced muscle activity regulates distinct gene signaling pathways in humans with spinal cord injury. PLoS One. 2014;22:9(12): e115791. 
49. Adams CM, Suneja M, Dudley-Javoroski S, Shields RK. Altered mRNA expression after long-term soleus electrical stimulation training in humans with paralysis. Muscle Nerve. 2011;43(1):65-75.

50. Shields RK, Dudley-Javoroski S. Musculoskeletal plasticity after acute spinal cord injury: effects of long term neuromuscular electrical stimulation training. J Neurophysiol. 2006;95(4):2380-2390.

51. Andersen JL, Mohr T, Biering-Sorensen F, Galbo H, Kjaer M. Myosin heavy chain isoform transformation in single fibres from $\mathrm{m}$. vastus lateralis in spinal cord injured individuals: effects of long-term functional electrical stimulation (FES). Pflugers Arch. 1996;431(4):513-518.

52. Mohr T, Andersen JL, Biering-Sorensen F, et al. Long-term adaptation to electrically induced cycle training in severe spinal cord injured individuals. Spinal Cord. 1997;35(1):1-16.

53. Dolbow DR, Gorgey AS, Dolbow JD, Gater DR. Seat pressure changes after eight weeks of functional electrical stimulation cycling: a pilot study. Top Spinal Cord Inj Rehabil. 2013;19(3):222-228.

54. Petrofsky JS. Functional electrical stimulation, a two year study. J Rehabil. 1992;58(3):29-34.
55. Hjeltnes N, Aksnes AK, Birkeland KI, Johansen J, Lannem A, Wallberg-Henriksson $\mathrm{H}$. Improved body composition after $8 \mathrm{wk}$ of electrically stimulated leg cycling in tetraplegic patients. Am J Physiol. 1997;273 (3Pt 2):R1072-R1079.

56. Dietz V. Body weight supported gait training: from laboratory to clinical setting. Brain Res Bull. 2008;76(5):459-463.

57. Behrman AL, Bowden MG, Nair PM. Neuroplasticity after spinal cord injury and training: an emerging paradigm shift in rehabilitation and walking recovery. Phys Ther. 2006;86(10):1406-1425.

58. Stevens SL, Caputo JL, Fuller DK, Morgan DW. Effects of underwater treadmill training on leg strength, balance, and walking performance in adults with incomplete spinal cord injury. J Spinal Cord Med. 2015;38(1):91-101.

59. Figoni SF, McClain L, Bell AA, Degnan JM, Norbury NE, Rettele RR. Accessibility of physical fitness facilities in the Kansas City metropolitan area. Top Spinal Cord Inj Rehabil. 1998;(3):66-78.

60. Dolbow DR, Figoni SF. Accommodation of wheelchair-reliant individuals by community fitness facilities. Spinal Cord. 2015;53(7):515-519.
Journal of Neurorestoratology

\section{Publish your work in this journal}

The Journal of Neurorestoratology is an international, peer-reviewed, open access online journal publishing original research and review articles on the subject of Neurorestoratology. To provide complete coverage of this revolutionary field the Journal of Neurorestoratology will report on relevant experimental research, technological advances, and

\section{Dovepress}

clinical achievements. The manuscript management system is completely online and includes a very quick and fair peer-review system, which is all easy to use. Visit http://www.dovepress.com/testimonials.php to read real quotes from published authors.

Submit your manuscript here: http://www.dovepress.com/journal-of-neurorestoratology-journal 